\title{
The role of collegiality in academic review, promotion, and tenure
}

\author{
Diane Dawson ${ }^{1 *}$, Esteban Morales ${ }^{2}$, Erin C. McKiernan ${ }^{3}$, Lesley A. Schimanski ${ }^{4}$, Meredith T. \\ Niles $^{5}$, Juan Pablo Alperin ${ }^{6 *}$ \\ ${ }^{1}$ University of Saskatchewan \\ ${ }^{2}$ University of British Columbia \\ ${ }^{3}$ Universidad Nacional Autónoma de México \\ ${ }^{4}$ Capilano University \\ ${ }^{5}$ University of Vermont \\ ${ }^{6}$ Simon Fraser University \\ ${ }^{*}$ Corresponding Authors \\ diane.dawson@usask.ca \\ juan@alperin.ca
}

\begin{abstract}
Review, promotion, and tenure (RPT) processes at universities typically assess candidates along three dimensions: research, teaching, and service. In recent years, some have argued for the inclusion of a controversial fourth criterion: collegiality. While collegiality plays a role in the morale and effectiveness of academic departments, it is amorphic and difficult to assess, and could be misused to stifle dissent or enforce homogeneity. Despite this, some institutions have opted to include this additional element in their RPT documents and processes, but it is unknown the extent of this practice and how it varies across institution type and disciplinary units. This study is based on two sets of data: survey data collected as part of a project that explored the publishing decisions of faculty and how these related to perceived importance in RPT processes, and 864 RPT documents collected from 129 universities from the United States and Canada. We analysed these RPT documents to determine the degree to which collegiality and related terms are mentioned, if they are defined, and if and how they may be assessed during the RPT process. Results show that when collegiality and related terms appear in these documents they are most often just briefly mentioned. It is less common for collegiality and related terms to be defined or assessed in RPT documents. Although the terms are mentioned across all types of institutions, there is a statistically significant difference in how prevalent they are at each. Collegiality is more commonly mentioned in the documents of doctoral researchfocused universities $(60 \%)$, than of master's universities and colleges $(31 \%)$ or baccalaureate colleges (15\%). Results from the accompanying survey of faculty also support this finding: individuals from R-Types were more likely to perceive collegiality to be a factor in their RPT processes. We conclude that collegiality likely plays an important role in RPT processes, whether it is explicitly acknowledged in policies and guidelines or not, and point to several strategies in how it might be best incorporated in the assessment of academic careers.
\end{abstract}

\section{Funding}

Funding for this project was provided to JPA, MTN, ECM, and LAS from the Open Society Foundations (OR2018-46345). The funders had no role in study design, data collection and analysis, decision to publish, or preparation of the manuscript. 


\section{Introduction}

Academic career progression in the United States and Canada is governed by review, promotion, and tenure (RPT) processes that typically assess candidates along three dimensions: research, teaching, and service. Although there is an increasing expectation that faculty should excel in all three dimensions [1], achievements in these three areas are not often weighed equally depending on the institution type, nor are they necessarily enough to guarantee a successful performance review or a promotion. Previous studies, including our own, have documented how research is often the most valued aspect of faculty work [2-6], with teaching second, and service activities a distant third $[5,7,8]$. However, it seems that even excelling in all three dimensions may not be enough. An additional, and controversial, characteristiccollegiality - has been the subject of robust debate [9-11], with some arguing for it to be added as a fourth dimension [e.g., 12,13], while others, notably the American Association of University Professors (AAUP), contend that if collegiality is to be assessed at all, it be within the three conventional categories [14].

There are two common understandings of the concept of collegiality. The first is captured by the Canadian Association of University Teachers (CAUT) that defines collegiality as the participation of academic staff in the collegial governance of the institution and states clearly that it "does not mean congeniality or civility" [15]. This form of collegiality is generally considered to reside under a faculty member's service obligations. A second understanding is aptly defined by Cipriano \& Buller [16]: "Collegiality is instantiated in the relationships that emerge within departments and in the manner in which members of the department interact with and show respect for one another, work collaboratively in order to achieve common purposes, and assume equitable responsibilities for the good of the unit as a whole" (p. 46). Indeed, many in academia would acknowledge that a well-functioning department relies on the collaborativeness and constructive cooperation of its members. Supportiveness, respectfulness, and willingness to contribute all play a role in the morale and effectiveness of the academic department. In fact, research shows that these kinds of collegial behaviors contribute to institutional effectiveness [13]. Collegiality among members of their department and/or the university was by far the most cited issue by faculty in a study of workplace satisfaction or dissatisfaction by Ambrose et al. [17].

While perhaps universally desired, collegiality is amorphous and subjective in nature, and thus difficult to assess fairly. In their statement, the AAUP notes that the inclusion of collegiality as a distinct criterion in RPT processes could be used as a cover for discrimination or to stifle dissent, effectively becoming a mechanism for enforcing homogeneity of thought or opinion to the detriment of the ideals of academic freedom for which tenure was established in the first place [14]. This is especially troubling if administrators attempt to intimidate or dissuade faculty from publicly questioning their decisions by accusing them of incivility or uncollegiality [18]. One response, from those who share these concerns but still support having collegiality assessed, could be to consider developing "equitable definitions of collegiality and clear measures that do not promote homogeneity, hinder academic freedom, or permit discrimination but that allow bad behaviour, such as bullying, to be addressed" [9]. One step further could involve adopting instruments to assist in fair assessment such as the Faculty Disposition Rubric [19,20], the 
Collegiality Assessment Matrix [10,16], or a validated tool created by researchers at the University of Tampa to assess indicators of discretionary behavior [13,21].

Although not everyone agrees with a formal assessment of collegiality in the RPT process, collegiality matters in academic life. For one, individuals and instances that violate collegial norms can disrupt the effective functioning of an academic unit, sometimes escalating to the point of bullying [see 22,23]. Such instances have, at times, resulted in the dismissal of individual faculty members. In the U.S., faculty members who have been denied tenure based on a perceived lack of collegiality have often sued their universities for violating their rights, with limited success [for a description of various court cases see $9,11,24$ ]. So far, the courts have consistently upheld the institutions' decisions in these cases, viewing these decisions as "an important factor in the ability of colleges and universities to fulfill their missions" [24] and have suggested that collegiality expectations be more formally included in employment contracts to provide clarity and avoid legal actions [13]. All this to say, when there are transgressions of collegial norms-perceived or real-there can be severe consequences for both individual academics and for the units and institutions they are a part of.

While some court rulings have advised institutions to incorporate collegiality expectations in their RPT documentation, it is unknown to what degree universities have in fact adopted such policies, or whether they continue to follow the AAUP's recommendation to avoid explicit assessment of collegiality. We are not aware of any studies that have sought to analyze, across various institution types and disciplinary units, how current RPT guidelines include the concept of collegiality. This study fills this gap by determining the extent to which the concept of collegiality (and related terms) is present in documents related to the RPT process. It is also unclear whether faculty perceive collegiality to be a factor in these processes, whether it is explicitly stated in their RPT documents or not. In doing so, we answer the following four related research questions:

1. Do faculty consider collegiality to be a factor in RPT processes?

2. How often do terms related to collegiality appear in RPT documents, and how do these vary across various institution types and disciplinary units?

3. How is the concept of collegiality defined within these documents?

4. To what extent and in which ways do RPT documents call for collegiality to be formally assessed?

\section{Methods}

This study is based on the analysis of qualitative survey data collected as part of a project that explored the publishing decisions of faculty and how these related to perceived importance in RPT processes [see 25], and an analysis of 864 RPT documents collected from 129 universities from the United States and Canada and previously reported on in Alperin et al. [3] and McKiernan et al. [26]. Within this dataset of 864 documents are 381 unit-level documents from 60 of the 129 universities. 


\section{Institution Sample and Document Collection}

The documents were collected from a representative sample of universities from the United States and Canada in 2016 and 2017. The sample of institutions was stratified based on institution type using the 2015 edition of the Carnegie Classification of Institutions of Higher Education [27] and the 2016 edition of the Maclean's University Rankings [28], which classify institutions into those focused on doctoral (i.e., research-intensive) programs (R-Type), those that predominantly focus on master's degrees (M-Type), and those focused on undergraduate (i.e., baccalaureate) programs (B-Type). Following this strategy, we were able to obtain documents from 381 academic units of 60 universities (out of a set of 129 universities for which we obtained university-level documents). Full details of the sample selection and document collection strategy are available in Alperin et al. [3].

\section{Faculty Survey}

As described in Niles et al. [25], to develop the survey sample we searched for a page listing the faculty members at each of these 381 academic units (e.g., faculty, department, or school), and randomly selected up to five faculty members. We were able to identify 1,644 faculty from 334 of the 381 units spanning all 60 institutions (with some units not listing email addresses publicly, and some units not having five faculty members listed).

The selected participants were invited to participate in an online survey on September $17^{\text {th }}$, 2018, with reminders sent on a weekly basis until October $29^{\text {th }}, 2018$ to anyone who had not yet responded. A total of 338 people (22\%) from 55 different institutions provided their written informed consent and proceeded to respond to the survey. Of these, $84(25 \%)$ were faculty at Canadian institutions and the remaining 254 (75\%) were from the United States; 223 (66\%) were from doctoral research-intensive (R-Type) institutions, $111(32 \%)$ from master's universities or colleges (M-Type) institutions, and 4 (1\%) from baccalaureate colleges (B-Type) institutions. Responses were then anonymized, leaving only the institution type and discipline along with the survey responses for analysis, as per the research protocol filed with the Office of Research Ethics at Simon Fraser University (file number: 2018s0264).

In this paper, we report the results of two related questions from the survey that were previously unreported by Niles et al. [25]. The first question asked respondents to rank seven factors by their value in the RPT process. Of the 338 respondents to the survey, 268 respondents provided a full ranking of the factors presented to them. Ranked responses were counted using Microsoft Excel.

The second question was an open-ended follow-up asking respondents if there were any additional factors that they perceived as important for their RPT processes; 95 individuals provided responses which were then coded for the presence of the terms collegial or collegiality (collegiality), the presence of a similar term or concept (collegiality-related), and for other unrelated factors (other) (Table 1). Finally, some responses were coded as non-answers (i.e., respondents did not present a factor valued in the RPT process). All responses were coded by two independent coders (D.D. and E.M.) using the descriptions and examples in Table 1. A Kappa value of 0.89 was achieved for intercoder reliability [29]. The two coders met to discuss 
the seven answers (7\%) where they differed and were able to come to an agreement on those codes.

Table 1. Codes, definitions, and examples for the open-ended responses to this question in the survey: "Are there any other factors that you think are important for your review, promotion or tenure?"

\begin{tabular}{|l|l|l|}
\hline Code & Definition & Example \\
\hline Collegiality & The term collegial or collegiality is used. & $\begin{array}{l}\text { "Perceptions of collegiality } \\
\text { within a department play } \\
\text { an "invisibly" large role." }\end{array}$ \\
\hline Collegiality-related & $\begin{array}{l}\text { Concepts related to collegiality (such as } \\
\text { departmental citizenship, departmental } \\
\text { politics, being likeable, having good } \\
\text { relationships, professionalism) are } \\
\text { expressed. }\end{array}$ & $\begin{array}{l}\text { Rabble-rousers, } \\
\text { complainers, and } \\
\text { naysayers lose votes, I've } \\
\text { seen it." }\end{array}$ \\
\hline Other & $\begin{array}{l}\text { Concepts not related to collegiality are } \\
\text { presented. }\end{array}$ & $\begin{array}{l}\text { "We are in a medical } \\
\text { school, so - clinical } \\
\text { practice excellence is } \\
\text { needed." }\end{array}$ \\
\hline Non-answers & $\begin{array}{l}\text { Comments or other non-responses such } \\
\text { as "no" and "not that I can think of". }\end{array}$ & $\begin{array}{l}\text { "No - it is a pretty } \\
\text { comprehensive list with } \\
\text { the broad categories } \\
\text { given." }\end{array}$ \\
\hline
\end{tabular}

RPT Document Querying, Coding, and Analysis

We loaded the full dataset of RPT documents into the NVivo 12 qualitative data analysis software [30] and queried the documents for collegiality and the related terms we identified through the analysis of the open-ended survey responses and from a review of the literature. We searched for the terms "collegial" or "collegiality" (resulting in 681 references across 228 documents), "citizen" or "citizenship" (resulting in 241 references across 134 documents), and "professionalism" (resulting in 103 references across 67 documents). While these are not the only terms that could be associated with the concept of collegiality, a preliminary reading of the RPT documents suggested they were the ones most commonly used to describe the concept, while other related terms (e.g., "respect") were primarily found in further descriptions or definitions of those three terms.

One person (D.D.) coded each of these references into one of three descriptive codes: mentioned, defined, and assessed using the descriptions and examples in Table 2. A randomly selected sample of 50 references was independently coded by another person (E.M.) to verify accuracy. A Kappa value of 0.89 was achieved for intercoder reliability. A fourth code was used to identify mentions that used the key terms in ways and contexts that were not considered 
relevant for this study, which led to the exclusion of $338(33 \%)$ irrelevant references [more details in the accompanying dataset 31].

Table 2. Codes, definitions, and examples for the qualitative analysis of the RPT documents

\begin{tabular}{|c|c|c|c|}
\hline Code & Brief Definition & Use this Code When: & Examples \\
\hline Mentioned & $\begin{array}{l}\text { Term is mentioned in } \\
\text { context relevant to } \\
\text { this study but without } \\
\text { being defined and } \\
\text { without details given } \\
\text { on how it will be } \\
\text { assessed. }\end{array}$ & $\begin{array}{l}\text { - Instance is isolated use of the } \\
\text { term (e.g. is mentioned in } \\
\text { passing among a list of other } \\
\text { desirable } \\
\text { characteristics/behaviors in } \\
\text { the candidate) OR } \\
\text { - Instance consists of an } \\
\text { example but no definition OR } \\
\text { - Instance appears in a } \\
\text { statement that it is considered } \\
\text { or assessed in RPT } \\
\text { processes but with no further } \\
\text { elaboration (no definition or } \\
\text { guidance on how to assess). }\end{array}$ & $\begin{array}{l}\text { "Collegiality, } \\
\text { cooperativeness, and } \\
\text { willingness to mentor } \\
\text { junior faculty would } \\
\text { be important } \\
\text { behavioral attributes." }\end{array}$ \\
\hline Defined & $\begin{array}{l}\text { More than a mention. } \\
\text { The term is defined or } \\
\text { elaborated upon, } \\
\text { often with examples. }\end{array}$ & $\begin{array}{l}\text { - Instance includes a definition } \\
\text { or description of the term, and } \\
\text { possibly a list of two or more } \\
\text { examples of behaviors } \\
\text { considered representative of } \\
\text { the term OR } \\
\text { - Instance does not include a } \\
\text { definition but includes enough } \\
\text { specific examples of } \\
\text { behaviors that the meaning of } \\
\text { the term is clear. }\end{array}$ & $\begin{array}{l}\text { "Collegiality is more } \\
\text { than civility and } \\
\text { getting along with } \\
\text { colleagues, staff, } \\
\text { students and others in } \\
\text { all university } \\
\text { environments; rather } \\
\text { it is consistent } \\
\text { behaviors that show } \\
\text { respect for others, } \\
\text { cooperative and } \\
\text { converted efforts to } \\
\text { achieve department, } \\
\text { college, and } \\
\text { university goals, and } \\
\text { the assumption of } \\
\text { responsibilities for the } \\
\text { good of the whole. } \\
\text { Hallmarks of } \\
\text { collegiality include, } \\
\text { but are not limited to, } \\
\text { cooperative } \\
\text { interaction, open and } \\
\text { honest } \\
\text { communication, } \\
\text { mutual support, } \\
\text { respect, and trust of } \\
\text { others, and } \\
\text { collaborative efforts }\end{array}$ \\
\hline
\end{tabular}




\begin{tabular}{|c|c|c|c|}
\hline & & & $\begin{array}{l}\text { toward the common } \\
\text { mission." }\end{array}$ \\
\hline Assessed & $\begin{array}{l}\text { More than a } \\
\text { definition. Includes a } \\
\text { description of how } \\
\text { the term is going to } \\
\text { be assessed in the } \\
\text { RPT process. }\end{array}$ & $\begin{array}{l}\text { - Instance includes instructions } \\
\text { or suggestions to candidates } \\
\text { on how to present evidence of } \\
\text { the term (e.g. write a } \\
\text { statement outlining your } \\
\text { collegial behaviors) OR } \\
\text { - Instance includes instruments } \\
\text { or rubrics to assess the } \\
\text { candidate on the term (e.g. a } \\
\text { survey to distribute to } \\
\text { colleagues, an assessment } \\
\text { form or checklist, etc.) OR } \\
\text { - Instance includes what will be } \\
\text { considered as evidence of the } \\
\text { term for RPT } \\
\text { evaluation/assessment } \\
\text { purposes. Note: This goes } \\
\text { beyond a list of example } \\
\text { behaviours (such as in the } \\
\text { "Defined" code), and includes } \\
\text { clear direction that certain } \\
\text { types of evidence will be used } \\
\text { to assess the candidate on } \\
\text { this term. } \\
\text { Note: If the document uses the } \\
\text { word "assessment" but it doesn't } \\
\text { describe how the term is } \\
\text { assessed, then it is coded as } \\
\text { either "Mentioned" or "Defined" }\end{array}$ & $\begin{array}{l}\text { "For each of the four } \\
\text { areas of professional } \\
\text { responsibility } \\
\text { (teaching, } \\
\text { scholarship, service, } \\
\text { collegiality), tenured } \\
\text { and tenure track } \\
\text { faculty members will } \\
\text { evaluate all other } \\
\text { tenured and tenure } \\
\text { track faculty members } \\
\text { of the department, } \\
\text { using the scale } \\
\text { described below." }\end{array}$ \\
\hline
\end{tabular}

Following the method described in Alperin et al. [3] and McKiernan et al. [26], we performed a "matrix coding query" to produce a table with institutions and academic units as rows, codes as columns, and a 1 or a 0 indicating whether the institution or academic unit made mention of the term or not, with the ability to distinguish if the mention appeared in documents that pertain to the whole institution, to one or more academic units, or both. We considered an institution as making mention of a term if the term was present in at least one document from that institution or any of its academic units.

\section{Results}

Research Question 1: Do faculty consider collegiality to be a factor in RPT processes? Overall, when asking respondents to rank the most important factor for RPT, they ranked research as the most important (mean 1.60), followed by teaching (mean 2.69), and grants (mean 3.33) (Figure 1). 


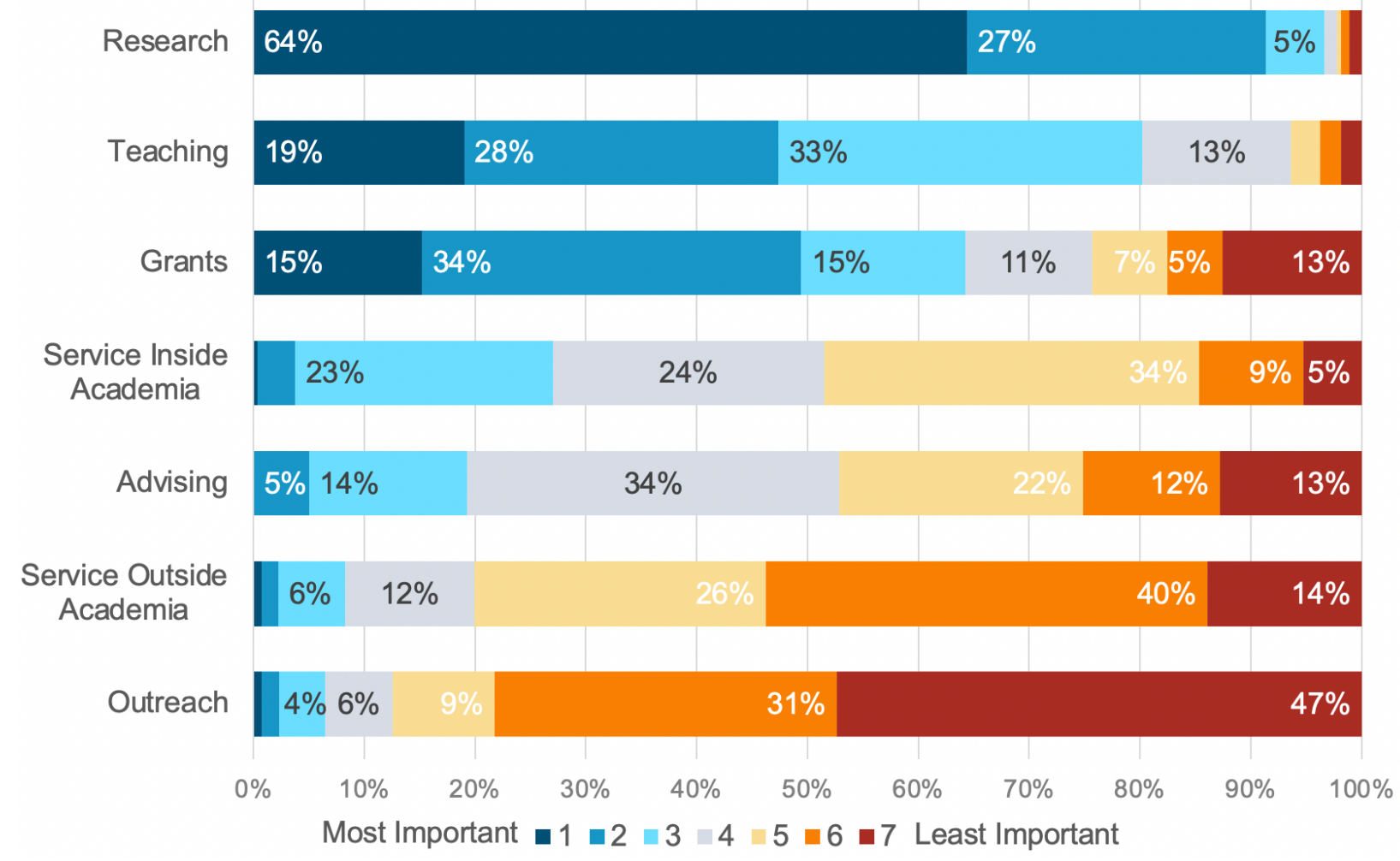

Figure 1. Survey respondents' ranking of factors in response to the question: "Which of the following do you think is the most important for your review, promotion or tenure?" Ranked in order of 1 (most important) to 7 (least important). Factors are ordered in their overall rate of importance (i.e., percent of respondents indicating a 1, 2, or 3).

The open-ended follow-up question in the survey asked whether there were other factors, not offered for ranking in the previous question, that respondents thought were important in their RPT processes. There were 95 respondents to this question, and all were from M-type or Rtype institutions. Of these 95 responses, 39 (41\%) indicated that collegiality or related concepts were a factor in RPT processes at their institutions (Table 3). This proportion was greater (55\%) after discarding responses that did not contain a concrete proposal (e.g., those that said "none"). Of these 39, 12 respondents used the exact term collegiality, while a further 27 respondents used other language to describe collegiality-related concepts (see examples of each in Table 4). 
Table 3. Coding results for open-ended survey question: "Are there any other factors that you think are important for your review, promotion, or tenure?"

\begin{tabular}{lrr|r}
\hline Code & M-type & R-type & Total \\
\hline Collegiality & 4 & 8 & 12 \\
Collegiality-related terms & 7 & 20 & 27 \\
Other & 7 & 25 & 32 \\
Non-answers & 11 & 13 & 24 \\
\hline Total & 29 & 66 & 95 \\
\hline
\end{tabular}

N.B.: There were no respondents from B-type institutions to this question.

Table 4. A selection of open-ended survey responses coded as either collegiality or collegiality-related

\begin{tabular}{|c|c|}
\hline Collegiality & Collegiality-related \\
\hline $\begin{array}{l}\text { "Collegiality, integrity (academic and } \\
\text { otherwise), general impression made on other } \\
\text { faculty members and the tenure committees } \\
\text { (departmental and faculty)." } \\
\text { "We are also judged on "collegiality", which is } \\
\text { nebulous due to a lack of clear policy on the } \\
\text { criteria." } \\
\text { "Perceptions of collegiality within a } \\
\text { department play an "invisibly" large role." } \\
\text { "Yes, collegiality among Faculty and } \\
\text { Students." } \\
\text { "Collegiality." }\end{array}$ & $\begin{array}{l}\text { "Playing the game. It's very much still } \\
\text { personality based in many regards." } \\
\text { "To be likeable and not cause too many } \\
\text { waves, especially if you are a person of color } \\
\text { or women." } \\
\text { "The most important factor [is] internal politics } \\
\text { and whether your colleagues like you. If they } \\
\text { do, they will fight for your tenure regardless. If } \\
\text { not, they will sink your tenure case." } \\
\text { "Departmental citizenship. Rabble-rousers, } \\
\text { complainers, and naysayers lose votes, I've } \\
\text { seen it." } \\
\text { "Professionalism: internally with colleagues } \\
\text { and participation in professional association." }\end{array}$ \\
\hline
\end{tabular}


Research Question 2: How often are terms related to collegiality referred to in RPT documents, and how do the references vary across various institution types and disciplinary units?

In the dataset of 864 RPT documents from 129 universities, the concept of collegiality (including related terms) was mentioned 507 times across 213 documents, defined 106 times across 85 documents, and assessed 51 times across 30 documents.

The concept of collegiality (including related terms) was mentioned across all types of institutions (R-Type, M-Type, and B-Type), and was defined or assessed only by a small proportion of R-Type and M-Type institutions (Table 5). These concepts were more prevalent at $\mathrm{R}$-Type institutions (approximately twice as prevalent, when compared to M-Types), and least common at B-Type institutions, where they were mentioned only infrequently and never defined or assessed (Table 5). Within the R-Type institutions, the concept was mentioned most frequently (61\%) in documents from Social Sciences and Humanities units, but was defined and assessed more frequently in those from the Life Sciences (24\% and 15\% respectively) (Table $6)$.

To determine whether the frequency in which collegiality was mentioned across types of institutions and disciplines were significantly different from a uniform distribution, we used a chisquare analysis. The null hypothesis for both analyses was that the overall proportion of documents mentioning collegiality was the same between the different categories. The alternative hypothesis was that the proportion of documents mentioning collegiality was not equal across all different categories included in the test. Results show statistically significant differences $(p<0.0001)$ in the number of times the concept of collegiality was mentioned across types of university (Table 5), but not when comparing across disciplines within the R-type institutions (Table 6) using a threshold of $p>0.05$.

Table 5. RPT documents' relevant references to collegiality and related terms by institution type

\begin{tabular}{lrr|rr|rr} 
& \multicolumn{2}{c|}{$\begin{array}{l}\text { R-Type } \\
\mathrm{N}=57\end{array}$} & \multicolumn{2}{c|}{$\begin{array}{c}\text { M-Type } \\
\mathrm{N}=39\end{array}$} & \multicolumn{2}{c}{$\begin{array}{c}\text { B-Type } \\
\mathrm{N}=33\end{array}$} \\
\hline Mentioned & 34 & $60 \%$ & 12 & $31 \%$ & 5 & $15 \%$ \\
Defined & 17 & $30 \%$ & 6 & $15 \%$ & 0 & $0 \%$ \\
Assessed & 7 & $12 \%$ & 3 & $8 \%$ & 0 & $0 \%$ \\
\hline
\end{tabular}

N.B. The conditions of the chi-square test were not met for the codes Defined or Assessed, but the chi-square analysis reveals the difference in the Mention of the concept of collegiality between institution types are significant. Chi-square tests: Code Mentioned: $\mathrm{X} 2(2, \mathrm{~N}=129)=19.11, \mathrm{p}<0.0001$. 
Table 6. RPT documents' relevant references to collegiality and related terms in R-Type institutions by discipline

\begin{tabular}{|c|c|c|c|c|c|c|c|c|}
\hline \multirow[b]{2}{*}{ Mentioned } & \multicolumn{2}{|c|}{$\begin{array}{c}\text { Social } \\
\text { Sciences and } \\
\text { Humanities } \\
\mathrm{N}=38\end{array}$} & \multicolumn{2}{|c|}{$\begin{array}{c}\text { Physical } \\
\text { Sciences \& } \\
\text { Mathematics } \\
\quad \mathrm{N}=20\end{array}$} & \multicolumn{2}{|c|}{$\begin{array}{l}\text { Life Sciences } \\
\qquad N=33\end{array}$} & \multicolumn{2}{|c|}{$\begin{array}{c}\text { Multi- } \\
\text { disciplinary } \\
N=22\end{array}$} \\
\hline & 23 & $61 \%$ & 8 & $40 \%$ & 14 & $42 \%$ & 8 & $36 \%$ \\
\hline Defined & 6 & $16 \%$ & 4 & $20 \%$ & 8 & $24 \%$ & 4 & $18 \%$ \\
\hline Assessed & 4 & $11 \%$ & 1 & $5 \%$ & 5 & $15 \%$ & 0 & $0 \%$ \\
\hline
\end{tabular}

N.B. The conditions of the chi-square test were not met for the codes Defined or Assessed, but the chi-square analysis reveals the difference in the mention of the concept of collegiality between disciplines are not significant. Chi-square tests: Code Mentioned: $x 2(2, N=113)=4.46, p>0.05$.

Many of the RPT documents in the dataset that refer to collegiality or related terms do so either within the conventional three categories of research, teaching, and service (as advised by the AAUP), or else in an introductory section or preamble of the document. In most of these references, the term is mentioned in passing without being defined and without details given on whether or how it will be assessed. For example, the College of Education and Human Development at Texas A \& M University-Corpus Christi has this sentence in the first paragraph of the preamble of their Promotion and Tenure Policy: "It is essential that faculty demonstrates dedication and achieves excellence in teaching, research/creative activity, professionalism, and professional contributions to preserve and strengthen the vitality of the university" [32]. The term professionalism is not referred to again in the document.

In another example, this time from the University of Utah, Department of Political Science, the documents incorporate collegiality into a conventional Service category. The following statement appears in the introductory paragraph of the Service section of their Policies and Procedures for Retention, Promotion, and Tenure of Regular Faculty document: "Service is a fundamental part of being a member of the faculty of the Department of Political Science. The management and collegiality of the department depends on members of the faculty participating in the work of the department" [33]. This is a typical example of the mentioned code in the dataset.

Research Question 3: How is the concept of collegiality defined within these documents?

We coded references to collegiality (and related terms) in the RPT documents as defined when the instances were more than a brief mention but do not go as far as discussing its assessment. In many of these instances the terms were defined or elaborated upon, often with or through examples.

The University of South Alabama, College of Arts and Sciences, provides this clear, concise definition with examples:

Collegiality is more than civility and getting along with colleagues, staff, students and others in all university environments; rather it is consistent behaviors that show respect for others, cooperative 
and converted efforts to achieve department, college, and university goals, and the assumption of responsibilities for the good of the whole. Hallmarks of collegiality include, but are not limited to, cooperative interaction, open and honest communication, mutual support, respect, and trust of others, and collaborative efforts toward the common mission [34].

Whereas, this example from Boise State University, Department of Psychological Science, begins with an explanation of the importance of collegiality with examples before giving a brief definition; although the definition is brief, the context provided with the examples makes the meaning clear:

In addition, the Department values collegiality in the consideration of a candidate for promotion and tenure. Faculty members do not operate in isolation from other departmental colleagues. We must make decisions together regarding the undergraduate curriculum, class offering [,] student advising, the allocation of resources and space, and the hiring of new faculty members. These decisions require cooperation and professional interaction. None of these tasks can be successfully completed if each faculty member acts solely in his or her own personal interest. Collegiality emphasizes civility and reciprocal working relationships among professionals, as would be expected in any other workplace of a professional nature [35].

Institutions often use similar terms such as: respect, civility, and cooperativeness when defining collegiality. These terms focus on personality characteristics, whereas other institutions highlight desirable professional attributes. This is illustrated in the definition provided by Cameron University's Department of History and Government:

Collegiality includes general professionalism in demeanor and appearance; a willingness to work with faculty, staff, and students on collective endeavors; a consistently demonstrated level of responsibility that includes prompt responses to email, telephone calls, and written correspondence, the submission of required administrative information, data, or reports on time, regular and prompt attendance at department or university meetings, knowledge of and adherence to all university policies, and a clear understanding of the proper professional line that should be drawn in faculty interactions with students [36].

Examples like this showcase the relationship between the terms collegiality and professionalism, the latter of which often appears within the category of teaching. Other related terms, like citizen or citizenship, usually occur within the service category, as in this definition from the University of Louisiana at Lafayette, Faculty Handbook which has a "Citizenship and Service" section:

The ideal faculty member is a model citizen of that community, helping to create an environment of collegiality. Such citizenship is manifested, for instance, in assuming administrative and leadership roles and in committee work at the department, college, and university levels. Institutional citizenship is displayed by assuming responsibility for improving the educational and research efforts of the institution, in counseling students about academic and personal matters, and in participating in the department's and University's outreach efforts in the community. Faculty are expected to treat all members of the campus community with respect and civility [37]. 
As in the examples above, when institutions include definitions of collegiality and related terms, they often do so within the existing categories of research, teaching, and service in adherence to the AAUP's recommendation. Several institutions refer directly to the AAUP statement [14], such as in this cautionary note from the University of Northern Colorado:

The requirement that review decisions (such as tenure and promotion) be based only on the results of comprehensive review in the areas of faculty endeavor (teaching, professional activity and service) precludes the use of collegiality as a separate dimension in making such decisions. The term collegiality has, historically, meant different things to different people. Sometimes, it indicates a legitimate concern for cooperativeness and team work. Sometimes, however, it has been used to foster an unhealthy uniformity of opinion that is a threat to academic freedom. The University of Northern Colorado adheres to the position of the AAUP by including the following note "On Collegiality As A Criterion for Faculty Evaluation" (November 1999). Collegiality should not be used as a separate category in reaching evaluative decisions. Where legitimate, it should be incorporated into the criteria for instruction, professional activity, and service [38].

Research Question 4: To what extent and in which ways do RPT documents call for collegiality to be formally assessed?

Some institutions went beyond mentioning and defining collegiality by providing some instructions or guidance on how it should be assessed. Formal assessment of collegiality in RPT documents is relatively rare, found only in the documents of only $8 \%$ of the institutions in our sample (12\% of R-Type institutions, $8 \%$ of M-Type, and in none of the B-Type). The instances found in our sample ranged from suggestions to solicit statements from colleagues of the candidate to more formal likert scale evaluation forms distributed to colleagues.

For example, the Tenure and Promotion Guidelines at McNeese State University states that collegiality should be assessed through statements from colleagues. The guidelines read: "Statements concerning collegiality should be based on evidence of respect for peers, willingness to work toward departmental goals, professionalism and other such factors. Evaluations shall not be tainted by undocumented or hearsay evidence" [39].

At one institution, assessment of collegiality is considered by the lack of evidence to the contrary. The University of South Alabama considers a candidate's collegiality only during tenure processes and it is treated as a fourth criterion in these cases. The College of Education includes this statement in their Tenure and Promotion Statement of Procedures and Criteria: "The criteria are the same as for promotion plus the additional important consideration of collegiality with the Candidate's department. Absence of evidence and argument to the contrary will be considered evidence of the Candidate's collegiality with the department" [40]. The College of Engineering includes very similar language [41]. Whereas the Pat Capps Covey College of Allied Health Professions includes this question, under its own category specific for Collegiality, for reviewers of the tenure candidate's file to consider: "Is the applicant compatible with colleagues in the Department?" [42].

Other universities take a mixed approach, taking both evidence and lack of evidence into account. For example, the University of Southern Mississippi, College of Education and 
bioRxiv preprint doi: https://doi.org/10.1101/2022.01.05.475103; this version posted January 5, 2022. The copyright holder for this preprint

Psychology, Department of Child and Family Studies, states in its Tenure and Promotion Guidelines that "Candidates are expected to demonstrate a continuing pattern of respecting and working well with peers, students, staff, and the unit's common purpose. Collegiality will be evaluated by the presence of a variety of positive indicators and the absence of negative indicators. Candidates are encouraged to address the issue of collegiality in the narrative they provide for review" [43]. The document goes on to provide a reasonably comprehensive, though not exhaustive, list of specific examples of positive and negative indicators of collegial behaviors. Several other departments within the College of Education and Psychology include similar language in their RPT guidelines. Interestingly, although these departments are quite thorough in defining and providing guidance on the assessment of collegiality, they stop short of explicitly listing it as a fourth criterion. Other Colleges and Departments at the University of Southern Mississippi similarly defined collegiality, but were explicit in indicating that it should not be considered a distinct performance category.

Contrary to the recommendations of the AAUP, some institutions or units treat collegiality as a fourth criterion in their RPT processes. The Southern Utah University (SUU), for example, provides what are arguably the most thorough guidelines for assessing collegiality from the documents in our sample. The guidelines are based on a university-level policy [44] that outlines faculty professional responsibilities to students, colleagues, and the institution, as well as disciplinary actions if the faculty member fails to meet the responsibilities. However, various departments within SUU assess it in different ways. For example, the Department of Accounting assesses faculty in each of the four categories yearly in a Faculty Annual Activity Report (FAAR). For the fourth category of Collegiality, candidates must demonstrate "Full compliance with SUU Policy 6.28 (latest edition), and achieve a five-year average score on collegiality of 0.80 from an anonymous survey of all department faculty members. The survey is completed by all department faculty members at the start of each academic year, and uses a two-point scale ( 0 = not collegial, and $1=$ collegial)" [45]. The Biology Department, on the other hand, requires candidates to write a summary statement of their collegiality for their RPT dossiers and provides a faculty survey for colleagues to assess the candidate using a 5 point scale on specific collegial attributes under the headings of "relationships with others" and "institutional citizen" [46]. And finally, the Psychology Department uses a Department Evaluation of Peers document wherein each faculty member assesses all other faculty members along a scale from Unacceptable to Meritorious in each of the four criteria of teaching, scholarship, service, and collegiality [47].

\section{Discussion}

Our survey of faculty revealed that beyond the typical criteria related to research, teaching, and service commonly evaluated in RPT processes, there are clear signs of an additional focus on the more intangible characteristic of collegiality. Among respondents who provided additional factors important for the RPT process, collegiality was the most common additional factor, suggested more often than all other responses combined. In searching for this concept in the RPT documents in our sample, we found that the prevalence of the related terms varied widely across institution types, appearing in the documents of only $15 \%$ of B-type institutions in our sample, but in $60 \%$ of those from the R-type institutions. Notably, while collegiality was mentioned in many of the RPT documents, far fewer defined the term and even fewer explained 
how collegiality was assessed. This apparent simultaneous reliance on, but ambiguity surrounding, the concept of collegiality could introduce potentially problematic subjective criteria and even bias into the RPT process by evaluators applying their own definitions of the concept [48].

Despite the overall prevalence of mentions, we found that it is rare for institutions to specify collegiality as a formal fourth criterion for evaluation in RPT documents. The majority of universities appear to adhere to the AAUP recommendation: if they refer to collegiality or related terms at all, it is usually within the three conventional categories (research, teaching, and service) or in a broad preamble statement. However, some authors have observed a growing trend in the use of collegiality in academic evaluations. In 2001, Connell and Savage reviewed the relevant U.S. court cases noting that "...courts have affirmed at every turn the use of collegiality as a factor in making decisions concerning faculty employment, promotion, tenure, and termination..." concluding that universities "...should feel confident in considering collegiality in faculty decisions and that it is unnecessary for them to specify collegiality as a separate and distinct criterion" [24]. In their follow-up study ten years later, Connell et al. [11] note that the trend of courts siding with institutions continues and that there is also an increase in universities "...using collegiality in making important employment decisions..." and adopting statements or policies regarding this (p. 572). Little appears to have been written about this in the Canadian context; we suspect this may be because most disputes are handled by appeal or grievance within the university and do not make it into the court system.

When collegiality or related terms are referred to in the RPT documents in our dataset, they are usually just mentioned briefly or in passing without further explanation or definition. Connell et al. [11] also found that when institutions make reference to collegiality they usually do so "...briefly or broadly in their tenure and promotion policies or faculty handbooks, but do not include it as a separate criterion for review" (p. 570). Briefly mentioning that collegiality is an important consideration, but not defining it, or outlining how it is to be assessed, potentially opens it up to being misinterpreted or abused in RPT decisions, potentially more than if RPT documents do not discuss collegiality at all. The danger is that the concept of collegiality can be weaponized to eliminate perceived "troublemakers" or those who do not "fit in" for various reasons. The concept of collegiality is highly subjective, but it can be argued that the terms and concepts used in assessing research are also subjective and lack clear definitions [49-51]. And Connell \& Savage [24] agree: "Although collegiality is a vague and subjective term, there is no question that evaluation of scholarship, research, and teaching is also very subjective" (p. 854). Despite the fact that collegiality is poorly defined, or not defined at all in RPT documents, some faculty still perceive that it plays a role, as the responses to the open-ended question in our survey reported in this study indicate.

The majority of respondents who provided answers to our survey question about other factors considered in RPT decisions were from R-Type institutions, which is commensurate with our response distribution of institutional types. Of the 39 responses that indicated collegiality or related factors were considered, 28 (71\%) were faculty from R-Type universities (as compared 
with $66 \%$ of the respondents), which corroborates our RPT analysis where collegiality and related terms were most prevalent in R-Type institutions.

That R-Type institutional respondents were most likely to mention collegiality is likely both a function of our distribution of respondents but also may be related to the nature of R-Type institutions. R-Type institutions are research intensive, as compared with M-Type or B-Type institutions, which may affect collegiality perspectives and experiences. In Generous Thinking: A Radical Approach to Saving the University [52], Kathleen Fitzpatrick identifies an individualistic and hyper-competitive environment of research universities as a key factor in faculty burnout and the undermining of collaborative relationships among colleagues. She further argues that RPT processes may be presented as meritocratic but "[i]n actual practice, however, those metrics are never neutral, and what we are measured against is far more often than not one another-sometimes literally" [52]. Such an environment can fuel resentments and disrespectful conduct among colleagues. These "perverse incentives" and a "pervasive culture of competition" actively discourage faculty from engaging in activities that would facilitate or contribute to the success of their colleagues [53]. Another possibility for the mentions of collegiality in R-type institutions, might be that these institutions have recognized the value of collegiality, which has led to the inclusion of the concept into evaluations. That is, that the greater presence of collegiality in the evaluation process and documents reflects the value placed on it by these institutions. Such an interpretation would be in opposition to Fitzpatrick, Agate, and their colleagues' view of these institutions, but would align with the reality that collaboration is implicitly incentivized on the research track through the citation advantage of multi-authored publications [54,55]. Finally, it is also possible that the inclusion of collegiality in documents is a function of the size of the institutions and of the academic unit's within them, something our study did not test. It may be that the relatively larger size of R-type institutions requires collegiality to be managed institutionally, while collegial relationships emerge more organically in smaller groups.

\section{Conclusions}

The results from our survey respondents in the United States and Canada suggest that the concept of collegiality plays a role in RPT decisions, even at institutions that do not explicitly acknowledge it as a factor in their processes or guidelines. This role may be indirect or informal as is suggested by the lack of definitions and assessment in RPT documents demonstrated through our assessment. However, despite the potential informal nature of collegiality in the RPT process, it must be acknowledged if we are to take seriously the concerns about the unfair influence of departmental politics, biases, and personal grievances that have emerged through court cases [9]. Acknowledging this role does not necessarily mean elevating collegiality to its own distinct criterion in the RPT process, which the AAUP [14] warns poses several dangers such as promoting homogeneity of thought, discouraging dissent, and acting as a cover for discrimination. Instead, universities or units could incorporate some kind of systematic approach to address collegiality within their existing evaluation frameworks that typically include the trifecta of research, teaching, and service. This could mean developing "clear definitions of teaching, scholarship, and service, in which the virtues of collegiality are reflected" as advised by the AAUP [14]. Encouraging collegial behaviors in this manner has the potential to improve 
the morale and job satisfaction of faculty while also increasing the overall effectiveness of the unit $[13,17]$.

While collaborative and collegial behaviors are necessary for the effective functioning of an academic unit and the contentment of its faculty, we must also recognize that it is complex to fairly assess collegiality, either as a criterion in RPT processes or as a dimension of other activities. Perhaps a values-enacted approach to assessment, as exemplified by the HuMetricsHSS initiative (https://humetricshss.org/) and discussed by Agate et al. [53], may present a viable means to include the aspects of collegiality that are desirable within a larger evaluation framework. As per Agate et al.'s approach, "values-enacted indicators" could be developed by each institution, or unit therein, to align with the core values or mission of the group, and a subset of these indicators, which they refer to as "vicarious indicators", could be used to recognize faculty who facilitate the success of colleagues through activities such as mentorship or providing formative reviews. Such an approach could reward this kind of traditionally undervalued labor while encouraging collegiality and collaboration. Agate et al. [53] note that this kind of evaluation is not unknown in the academy; administrators are often assessed on the success of those they lead. While none of the institutions that defined or assessed collegiality used a value-centric approach, there is ample opportunity for them to do so, especially as momentum continues to build towards research assessment reform [56-59].

\section{Limitations}

There are several limitations to the findings in this study, similar to the limitations mentioned in the previously published articles on this survey dataset [25] and this RPT document dataset [26]. Both the survey and the RPT documents have a geographic focus of Canada and the United States. We acknowledge that this means the findings are likely not representative of other regions globally. Additionally, the survey responses rely on the participants' self-reported information and perceptions of the importance of collegiality in RPT processes at their institutions. This may not align with the experiences of their colleagues or the stated practices of their units.

The types of documents collected in the RPT dataset are diverse: from university-level faculty handbooks to department-level standards and guidelines for RPT assessment and processes. As such, some of these documents contain more specific information than others regarding expectations of candidates. As such, the lack of presence of collegiality or related concepts may be due to the types of documents used at those institutions or assembled in our dataset, and not a lack of interest or focus on using this criterion for evaluation. Finally, studying the RPT process through a document-centric approach such as this limits our analysis to what is formalized in the documents themselves. This approach is further limited by the terms which we chose to include in our search, which itself may have excluded mentions of the concept that was expressed in ways we did not anticipate. A document-centric approach cannot tell us how RPT committees use collegiality or related concepts, if at all, during the process, nor how candidates use these guidelines in preparing their dossiers. The stated practices in these guidelines versus their actual application, or not, as well as the lived experiences of candidates and RPT committee members during the process, remain to be explored in future studies. 
bioRxiv preprint doi: https://doi.org/10.1101/2022.01.05.475103; this version posted January 5, 2022. The copyright holder for this preprint

\section{References}

1. Schimanski LA, Alperin JP. The evaluation of scholarship in academic promotion and tenure processes: Past, present, and future. F1000Research. 2018;7: 1-19. doi:10.12688/f1000research.16493.1

2. Acker S, Webber M. Discipline and Publish: The Tenure Review Process in Ontario Universities. In: Shultz L, Viczko M, editors. Assembling and Governing the Higher Education Institution: Democracy, Social Justice and Leadership in Global Higher Education. London: Palgrave Macmillan UK; 2016. pp. 233-255. doi:10.1057/978-1-13752261-0 13

3. Alperin JP, Muñoz Nieves C, Schimanski LA, Fischman GE, Niles MT, McKiernan EC. How significant are the public dimensions of faculty work in review, promotion and tenure documents? eLife. 2019;8. doi:10.7554/eLife.42254

4. Green RG, Baskind FR. The Second Decade of the Faculty Publication Project: Journal Article Publications and the Importance of Faculty Scholarship. J Soc Work Educ. 2007;43: 281-296. doi:10.5175/JSWE.2007.200600050

5. Harley D, Acord SK, Earl-Novell S, Lawrence S, King CJ. Assessing the Future Landscape of Scholarly Communication: An Exploration of Faculty Values and Needs in Seven Disciplines. 2010 p. 738. Available: http://escholarship.org/uc/item/15x7385g

6. Macfarlane B. Defining and Rewarding Academic Citizenship: The implications for university promotions policy. J High Educ Policy Manag. 2007;29: 261-273. doi:10.1080/13600800701457863

7. Fischman GE, Anderson KT, Tefera AA, Zuiker SJ. If Mobilizing Educational Research Is the Answer, Who Can Afford to Ask the Question? An Analysis of Faculty Perspectives on Knowledge Mobilization for Scholarship in Education. AERA Open. 2018;4: 2332858417750133. doi:10.1177/2332858417750133

8. Foos A, Holmes MA, O'Connell S. What Does It Take to Get Tenure? Geotimes. 2004;88: 38-39.

9. Blankenship-Knox BAE, Platt RE, Read H. Rewarding Collegiality: The Use of Collegiality as a Factor in Faculty Evaluation and Employment Decisions. J Fac Dev. 2017;31: 37-42.

10. Cipriano RE, Buller JL. Is collegiality a weapon or a shield? Change Mag High Learn. 2017;49: 53-61. doi:10.1080/00091383.2017.1265393

11. Connell MA, Melear KB, Savage FG. Collegiality in higher education employment decisions: The evolving law. J Coll Univ Law. 2011;37: 529-588.

12. Cipriano RE. Collegiality as a Fourth Criterion for Personnel Decisions. Dep Chair. 2015;25: 21-22. doi:10.1002/dch.30022

13. Johnston PC, Schimmel T, O'Hara H. Revisiting the AAUP recommendation: The viability of collegiality as a fourth criterion for university faculty evaluation. Coll Q Seneca Coll Appl Arts Technol. 2012;15. Available: http://www.collegequarterly.ca/2013-vol16-num01winter/huang-capps.html

14. American Association of University Professors. On collegiality as a criterion for faculty evaluation. Washington, DC; 2016 pp. 1-2. Available: https://www.aaup.org/report/collegiality-criterion-faculty-evaluation

15. Canadian Association of University Teachers. Collegiality: CAUT Policy Statement. 2010. Available: https://www.caut.ca/about-us/caut-policy/lists/caut-policy-statements/policystatement-on-collegiality

16. Cipriano RE, Buller JL. Rating Faculty Collegiality. Change Mag High Learn. 2012;44: 4548. doi:10.1080/00091383.2012.655219

17. Ambrose S, Huston T, Norman M. A Qualitative Method for Assessing Faculty Satisfaction. Res High Educ. 2005;46: 803-830. doi:10.1007/s11162-004-6226-6 
bioRxiv preprint doi: https://doi.org/10.1101/2022.01.05.475103; this version posted January 5, 2022. The copyright holder for this preprint

18. McDonald TW, Stockton JD, Landrum RE. Civility and Academic Freedom: Who Defines the Former (and How) May Imperil Rights to the Latter. Coll Q. 2018;21. doi:10.1016/j.matchemphys.2011.08.003

19. Boyce BA, Oates R, Lund J, Fiorentino L. Faculty collegiality and dispositions in the tenure and promotion process: Developing a performance rubric. Acad Lead. 2008;24: 3-5.

20. Lund J, Boyce BA, Oates R, Fiorentino L. Faculty Dispositions: Seeking Clarity While Looking at Muddy Waters. Quest. 2010;62: 268-286.

doi:10.1080/00336297.2010.10483648

21. Schimmel T, Johnston PC, Stasio M. Can "collegiality" be measured?: Further validation of a faculty assessment model of discretionary behaviors. Res High Educ J. 2013;21: 1-7.

22. Fogg P. Academic bullies. Chron High Educ. 2008;55: 10-13.

23. Keashly L, Neuman JH. Faculty Experiences with Bullying in Higher Education. Adm Theory Prax. 2010;32: 48-70. doi:10.2753/ATP1084-1806320103

24. Connell MA, Savage FG. The Role of Collegiality in Higher Education Tenure, Promotion, and Termination Decisions. J Coll Univ Law. 2001;27: 833-858.

25. Niles MT, Schimanski LA, McKiernan EC, Alperin JP. Why we publish where we do: Faculty publishing values and their relationship to review, promotion and tenure expectations. Useche SA, editor. PLOS ONE. 2020;15: e0228914. doi:10.1371/journal.pone.0228914

26. McKiernan EC, Schimanski LA, Muñoz Nieves C, Matthias L, Niles MT, Alperin JP. Use of the Journal Impact Factor in academic review, promotion, and tenure evaluations. eLife. 2019;8. doi:10.7554/eLife.47338

27. Carnegie Foundation for the Advancement of Teaching. The Carnegie Classifications of Institutions of Higher Education. 2015. Available: http://carnegieclassifications.iu.edu/

28. Rogers Digital Media. Maclean's University Rankings. 2016. Available: https://www.macleans.ca/education/unirankings

29. McHugh ML. Interrater reliability: the kappa statistic. Biochem Medica. 2012; 276-282. doi:10.11613/BM.2012.031

30. QSR International Pty Ltd. NVivo 12. 2020.

31. Niles MT, Schimanski LA, McKiernan EC, Alperin JP. Survey responses about review, tenure, and promotion. Harvard Dataverse; 2021. doi:10.7910/DVN/MRLHNO

32. Texas A \& M University-Corpus Christi - College of Education and Human Development. Promotion and Tenure Policy. College of Education and Human Development; 2015.

33. University of Utah - Department of Political Science. Policies and Procedures for Retention, Promotion, and Tenure of Regular Faculty. 2012.

34. University of South Alabama - College of Arts and Sciences. Tenure and Promotion Statement of Procedures and Criteria. 2017.

35. Boise State University - Department of Psychological Science. Guidelines for Promotion and Tenure. 2017.

36. Cameron University - Department of History and Government. Guidelines for Departmental Evaluation, Promotion, and Tenure. 2010.

37. University of Louisiana at Lafayette. Faculty Personnel Policies. Faculty handbook. 2016.

38. University of Northern Colorado. Board Policy Manual. 2016.

39. McNeese State University. Tenure and Promotion Guidelines. 2015.

40. University of South Alabama - College of Education. Tenure and Promotion Statement of Procedures and Criteria. 2016.

41. University of South Alabama - College of Engineering. Tenure and Promotion Statement of Procedures and Criteria. 2012.

42. University of South Alabama - Pat Capps Covey College of Allied Health Professions. olicies and Procedures Manual. 2016. 
43. University of Southern Mississippi- Department of Child and Family Studies. Tenure and Promotion Guidelines. 2011.

44. Southern Utah University. Policy 6.28: Faculty professional responsibility. 2012. Available: https://help.suu.edu/uploads/attachments/PP628Faculty.pdf

45. Southern Utah University - Department of Accounting. Minimum Performance Standards for the Department of Accounting. 2006.

46. Southern Utah University - Biology Department.

47. Southern Utah University - Psychology Department. Leave, Rank and Tenure (LRT) Policy. 2011.

48. Hatch A, Curry S. Changing how we evaluate research is difficult, but not impossible. eLife. 2020;9. doi:10.7554/eLife.58654

49. Hatch A. To fix research assessment, swap slogans for definitions. Nature. 2019;576: 9-9. doi:10.1038/d41586-019-03696-w

50. Moore S, Neylon C, Paul Eve M, Paul O’Donnell D, Pattinson D. "Excellence R Us": university research and the fetishisation of excellence. Palgrave Commun. 2017;3: 16105. doi:10.1057/palcomms.2016.105

51. Morales E, McKiernan EC, Niles MT, Schimanski L, Alperin JP. How faculty define quality, prestige, and impact of academic journals. PLOS ONE. 2021;16: e0257340. doi:10.1371/journal.pone.0257340

52. Fitzpatrick K. Generous Thinking: A Radical Approach to Saving the University. Baltimore, Maryland: Johns Hopkins University Press; 2019.

53. Agate N, Kennison R, Konkiel S, Long CP, Rhody J, Sacchi S, et al. The transformative power of values-enacted scholarship. Humanit Soc Sci Commun. 2020;7: 165. doi:10.1057/s41599-020-00647-z

54. Bornmann L. Is collaboration among scientists related to the citation impact of papers because their quality increases with collaboration? An analysis based on data from F1000Prime and normalized citation scores. J Assoc Inf Sci Technol. 2017;68: 1036-1047. doi:10.1002/asi.23728

55. Larivière $V$, Gingras $Y$, Sugimoto $C R$, Tsou $A$. Team size matters: Collaboration and scientific impact since 1900. J Assoc Inf Sci Technol. 2015;66: 1323-1332. doi:10.1002/asi.23266

56. DORA. Good Practices - Funders - DORA. In: San Francisco Declaration on Research Assessment [Internet]. [cited 17 Sep 2018]. Available: https://sfdora.org/goodpractices/funders/

57. Hicks D, Wouters P, Waltman L, de Rijcke S, Rafols I. Bibliometrics: The Leiden Manifesto for research metrics. Nat News. 2015;520: 429. doi:10.1038/520429a

58. Moher D, Bouter L, Kleinert S, Glasziou P, Sham MH, Barbour V, et al. The Hong Kong Principles for assessing researchers: Fostering research integrity. PLOS Biol. 2020;18: e3000737. doi:10.1371/journal.pbio.3000737

59. Wilsdon J, Allen L, Belfiore E, Campbell P, Curry S, Hill S, et al. The metric tide : report of the Independent Review of the Role of Metrics in Research Assessment and Management. 2015. doi:10.13140/RG.2.1.4929.1363 